\title{
Correction: Mitochondrial clearance by the STK38 kinase supports oncogenic Ras-induced cell transformation
}

\author{
Audrey Bettoun ${ }^{1}$, Carine Joffre ${ }^{1,5, *}$, Giulia Zago ${ }^{1, *}$, Didier Surdez ${ }^{1}$, David Vallerand ${ }^{1}$, \\ Ramazan Gundogdu' ${ }^{2}$, Ahmad A.D. Sharif², Marta Gomez ${ }^{2}$, Ilaria Cascone ${ }^{1}$, Brigitte \\ Meunier ${ }^{1}$, Michael A. White ${ }^{3}$, Patrice Codogno ${ }^{4}$, Maria Carla Parrini ${ }^{1}$, Jacques $\mathbf{H}$. \\ Camonis $^{1}$ and Alexander Hergovich ${ }^{2}$ \\ ${ }^{1}$ Institut Curie, Inserm U830, Paris Sciences et Lettres University Paris, 75248, France \\ ${ }^{2}$ University College London, Cancer Institute, London, WC1E 6BT, United Kingdom \\ ${ }^{3}$ University of Texas Southwestern Medical Center, Dallas, Texas, 75390, USA \\ ${ }^{4}$ Inserm U1151-CNRS UMR 8253, Institut Necker Enfants-Malades, Paris, 75993, France \\ ${ }^{5}$ Present address: Cancer Research Center of Toulouse, UMR1037, Toulouse, 31100, France \\ * These authors have contributed equally to this work \\ Published: April 27, 2018
}

Copyright: Bettoun et al. This is an open-access article distributed under the terms of the Creative Commons Attribution License 3.0 (CC BY 3.0), which permits unrestricted use, distribution, and reproduction in any medium, provided the original author and source are credited.

This article has been corrected: The correct Grant Support information is given below:

\section{GRANT SUPPORT}

This work was supported by the Wellcome Trust Research Career Development fellowship 090090/Z/09/Z (to A. Hergovich); the BBSRC grant BB/I021248/1 (to A. Hergovich); the National Institute for Health Research University College London Hospitals Biomedical Research Centre; the Ministry of National Education of the Republic of Turkey (to R. Gundogdu); the Ligue Nationale contre le cancer (LNCC) grants RD14/75-80 (to J. Camonis) and RS14/75-54 (to M.C. Parrini); the Fondation ARC grant SFI20121205710 (to M.C. Parrini); the ARC grant SFI20111203931 (to J. Camonis); the ANR grant ANR-13-CESA-0010-001 (to P. Codogno); the Association Christelle Bouillot; INCA; and institutional INSERI and CNRS funding. Work was supported also by grant ANR-08-NLAN-0290-01 to J. Camonis.

Original article: Oncotarget. 2016; 7:44142-44160. https://doi.org/10.18632/oncotarget.9875 